InOedia $\quad \begin{aligned} & \text { InMedia } \\ & \text { The French Journal of Media Studies }\end{aligned}$

8.1. $\mid 2020$

Ubiquitous Visuality

\title{
Touch and See? Regarding Images in the Era of the Interface
}

\section{Martine Beugnet}

\section{(2) OpenEdition \\ 1 Journals}

\section{Electronic version}

URL: http://journals.openedition.org/inmedia/2102

DOI: 10.4000/inmedia.2102

ISSN: 2259-4728

\section{Publisher}

Center for Research on the English-Speaking World (CREW)

\section{Electronic reference}

Martine Beugnet, "Touch and See? Regarding Images in the Era of the Interface", InMedia [Online], 8.1. I 2020, Online since 15 December 2020, connection on 26 January 2021. URL: http:// journals.openedition.org/inmedia/2102 ; DOI: https://doi.org/10.4000/inmedia.2102

This text was automatically generated on 26 January 2021.

(c) InMedia 


\title{
Touch and See? Regarding Images in the Era of the Interface
}

\author{
Martine Beugnet
}

\section{AUTHOR'S NOTE}

This text is part of a larger research project on digital media, figurations and gestures. My thanks to Jane Sillars for her enlightening comments on the initial version. This article was also nourished by discussions that took place as part of the English Studies' Imaginaires contemporains seminars at Université de Paris, as well as conferences (Le geste filmé, Temporalité, Mémoire, Labex Arts-H2H, INHA, Paris November 2015, Film Philosophy, Edinburgh, July 2016, IAMHIST, Paris I Panthéon-Assas, July 2017).

We are made one with what we touch and see Oscar Wilde, Panthea, 1881 Many of our gestures are still traditionally configured. Others surprise and sometimes repulse us. The new is always monstrous. Vilém Flusser, Les gestes, $2014^{1}$

\section{Introduction}

The fine, variable balance that rules over the potential impact of images on their viewers is shifting. As programmed technologies become ubiquitous and gradually come to determine our routine access to visual matter, so do the material conditions of reception play an ever-greater role in the effect images yield, arguably to the detriment of their content and form. In the era of the electronic and digital interface, visuality ${ }^{2}$ is not simply an issue of the capture, manipulation, and representation of the visible anymore, nor even one of image literacy ${ }^{3}$ and cultural status, but, increasingly, one of display and interface. ${ }^{4}$ The question of which images have the power to move us is 
becoming entangled with that of how we move images, or, rather, how technology allows us to do so.

2 Not only are we now surrounded by a plethora of "technical images" as Vilém Flusser would call them ${ }^{5}$-images that derive from automatic technical protocols-but vision itself is controlled by technological processes through which manually activated interfaces condition the appearance of images ${ }^{6}$ in terms of size, quality and resolution, as well as duration. Our experience as viewers increasingly become that of "users": we touch the screen to activate a menu and select a resolution, to choose and enlarge an image, zoom into it or reduce its size, to start or pause a video, to scroll through or superimpose images, to slow down or speed up their course, to make them disappear. Not that the involvement of the hand turns the interface into the equivalent of a tool, which is an extension of the body. Unlike the tool, touch screens (which allow for the handling of images in some ways comparable with the TV, VHS and DVD, remote control, but with an unmatched immediacy and broader span of operations) belong to the realm of the programmed machine. As such, and until we learn to subvert their intended usages-as Flusser pointed out-post-industrial technologies predetermine the form and meaning of the user's gestures as well as the quality of his or her perception. ${ }^{7}$

3 To evaluate the effect of technology over the culturality of gestures as well as vision was one of Flusser's key projects, one whose import comes to the fore with particular force in the digital era, when visuality appears to increasingly escape the realm of purely visual phenomenon. In what follows, I situate my argument in relation to Flusser's far-sighted work, as well as concepts of the fold as derived from Leibnitz and Gilles Deleuze by Laura U. Marks, as I focus on the ways in which the hand interfaces with images through tactile display devices. In turn, such processes of mediation or, to

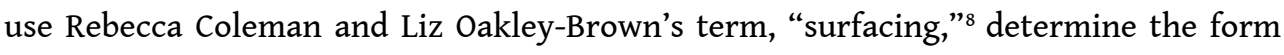
and effect of image reception in the context of our contemporary "economy of attention," as theorized by Jonathan Beller, Yves Citton and Jonathan Crary amongst others. ${ }^{9}$

4 To this end, I rely also on the description and critical assessment of Touching Reality (2012), by artist Thomas Hirschhorn, a video installation based on a deliberately controversial assemblage of interface and images, bringing the question of reception into sharp focus. Touching Reality is not an interactive work: it is a classical video projection that presents the viewer with the filmed gesture of interfacing. Correspondingly, though I am interested in the impact of tactile interfaces on contemporary modes of visual reception, the rich literature produced by the field of software studies is not the main focus of this article.${ }^{10}$ Closer to visual anthropology, ${ }^{11}$ and inspired by Flusser's phenomenological approach, this article does not so much emphasize the pervasiveness of computing and the technical or formal aspects of interfacing, as it dissects the ways in which the practice of interfacing affects our gestures, and may eventually overlay the initial meaning of a particular gesture. To put this process in the context of Hirschhorn's work, I address the following question: how does a gesture originally intended as a caress find itself associated with images of mutilated corpses? 


\section{Touching Reality: the unfolding of the poor image}

5 Thomas Hirschhorn's installation Touching Reality consists of a large screen of about 2 by 3 meters, on which a $6 \mathrm{mn}$ silent video plays in a loop. The video shows a touchscreen tablet, whose surface, captured in static shot, fills the frame: the two screens (the tablet's and that of the video installation) are thus superimposed. However, a hand appears continuously between the lens of the video camera and the screen of the computer pad that it films, a constant reminder of this dual-screen set up. The hand expertly manipulates the iPad, swiping to scroll through a series of images, zooming in with two fingers spread outwards, pinching to reduce the overall size of the image, lightly tapping the screen so that the image regains its original format: severed from the rest of its body by the limits of the frame, the hand operates the device with such agility that the video could almost stand as a "demo" of tactile interfaces. But to watch it in this way, as a kind of digital manipulation showpiece, one would have to ignore the images whose display the hand controls via the pad, images that are impossible to ignore, for what they show is the brutal reality of a world at war: corpses -the mutilated, disfigured, eviscerated bodies produced by armed conflicts.

In the manifesto that accompanies his work, Hirschhorn insists on the necessity of continuously looking at such images today-documentary images of violence, "poor images," ${ }^{12}$ shot with mobile phones, posted on the web. ${ }^{13}$ Although his call echoes W.J.T. Mitchell's argument that we must "own up" to what images of violence tell us, Hirschhorn sidesteps the iconological and archeological approaches exemplified by Mitchell's work. ${ }^{14}$ The series he assembled together for the video was gathered by the artist on the internet, paying no attention to their source or their quality, collecting seemingly random testimonies of the world's ongoing destruction so as to display them without attempting to filter, order or hierarchize. It is tempting to see in Hirschhorn's work a manifestation of what Laura U. Marks described, in her extrapolation of the Deleuzian "fold," as art's capacity to "unfold the enfolded." 15 For Marks, the continuity of the fold, as a model for the acquisition of knowledge, is imperilled by the increased filtering to which the data that may reach us is subjected, consciously or automatically, by digital modes of transmission. More efficiently than any of the mediating processes of the eras that preceded computing and the Internet 2.0, the digital conditions our perception and comprehension of the world, she argues, by preselecting, encoding, and transforming virtual images into information. ${ }^{16}$ One of contemporary art's roles may be to attempt to recoup that which has been marginalized or interpreted according to this set grid of conventions, and to "unfold" the information, making visible the ways in which it has previously been "encoded." 17

7 On the one hand, Touching Reality's treatment of images is evocative of Hito Steyerl's now classic manifesto for the poor image, which echoes Mark's advocacy of artistic "unfolding" in its defense of the significance and subversive value of the low definition images that now proliferate on our screens. ${ }^{18}$ Steyerl points to the importance of these images in spite of, or indeed because, they bear the mark of their encoding-the visible effect of low definition capture, as well as compression and repeated copying-thus rendering tangible the would-be seamless processes at work in digital communication. Their destabilizing potential further derives from a mode of dissemination that escapes established cultural hierarchies of the visual: often anonymous and visually degraded, "poor images" are circulated and shared without a pecking order. On the other hand, 
Hirschhorn's foregrounding of the swipe as a mode of handling visual matter, where the gliding touch of a finger appears to fold an image on top of another, directly evokes the fold and its layers of connected data as described by Laura U. Marks. However, to extend the meaning of "unfolding" to the description of this particular gesture is to associate contradictory forms of image "surfacing." ${ }^{19}$ For, whereas "unfolding" in Marks's sense works as a counterpoint to the processes of image encoding and filtering, the swipe is shaped by an interface that normalizes the mode that makes images appear. As such-and even more so when it functions perfectly, allowing for a clean, uninterrupted gliding gesture-it does not participate in a process of "unfolding," it merely works alongside the initial "enfolding" operated, for instance, by an image aggregating software. ${ }^{20}$

8 Such readings of Hirschhorn's work, however, fail to account for the installation as dispositif $f^{21}$ and as such, may obscure the more troubling and also, arguably, the more critical aspects of the artist's project. When recast as or incorporated in an art work, the poor image is subjected to a process of "artification" ${ }^{22}$ that, as will be discussed later, raises a number of issues: the accumulation of images selected for their violent content, yet devoid of context, begs the question of the standardization and devaluation of suffering. However, Touching Reality is a filmed version of the gesture of swiping through disturbing images; as a video installation, it therefore offers itself as a mise en abyme of the reception of such images. As a mode of display aimed at a collective audience, the installation relocates the intimacy implied by the tactile gesture within a broader practice and culture of images.

Before I turn to critical reviews of Hirschhorn's installation and interrogate the artist's choice of images and display in relation to the ongoing debate on the ethics of vision, I will focus on the user's gestures and, grounding my argument in Flusser's theory, question their performative as well as functional capacity. In the end, the combined reflection on images and interface leads me back, via the reflexive dimension of Hirschhorn's video work, to a broader examination on the modes of display and reception on today's tactile screens.

\section{From wipe to swipe: gesture, affect and epidermality}

In the introduction to his collection of essays on gestures, Flusser proposes a definition based on an elementary distinction: a gesture is neither a reflex, nor a simple movement. Contrary to the reflex (such as when we close our eyes because the light is too bright), a gesture is never purely instinctive. Nor can it be fully explained and interpreted by its causes. A gesture implies an intention, a decision, and therefore, a degree of free choice. Moreover, and in contrast with the basic movement, it is not arbitrary, that is, purely individual and punctual: the choice and freedom of making this or that gesture is circumscribed by a set of codes and conventions that contribute to the intelligibility and efficacy of the gesture. These codes operate in an intersubjective fashion: a gesture becomes meaningful through the relations it establishes with the world and others. ${ }^{23}$ Both socially and culturally determined, yet the manifestation of a choice, the gesture thus expresses what Flusser calls Gestimmtheit: a mode of being in the world. ${ }^{24}$ It therefore needs to be considered in relation to its material, social and historical context of emergence or obsolescence. ${ }^{25}$ 
11 Flusser's attempt to analyze and conceptualize gesture took place between the 1970s and the 1990s-that is, the period that preceded the banalization of digital technologies, and in particular the technologies of communication and touchscreens that have come to determine so blatantly today's prevailing range of human gestures. If Flusser's observations nonetheless retain their topicality, it is not only because the philosopher anticipated the effects of extreme technologizing, but also because he pointed to (and criticized), the functionalist tendency that dissociates a gesture from its object as well as the context where it operates. In our contemporary world, Flusser observed, the method and the technique were taking over: the main question was not "why?" or "to what aim?" anymore; we increasingly cease to concentrate on the meaning and effect of our gestures, to focus instead on the "how?"26 Gestures thus gradually veered towards the domain of pure functionality, or, to borrow a term proposed by Francesco Casetti and Sara Sampietro in relation to portable touchscreens, "epidermal" uses ${ }^{27}$ : what matters is not the content any more, but the operating method to be mastered and applied with maximum efficiency. This evolution obviously comes at a price: Flusser denounces the growing reign of the "neutral" gesture, emptied of affect and bent on technical mastery, as the manifestation of a profound alienation. ${ }^{28}$

12 Although the set of gestures developed alongside electronic and digital technologies became a staple of our daily life well after Flusser wrote his study, the scholar's intuitions and his notion of Gestimmtheit continue to provide useful insight into the effect of new or re-contextualised gestures on our perception. They are pertinent, in particular, to the question of how technically determined gestures frame and potentially define our handling-literal as well as affective-of sensitive visual content. Flusser's method, including his attention to the genealogy and evolution of gestures and their annexation to different uses, proves precious in highlighting the changing significance of our mode of access to the visual, and, by extension, of our perception of and relation to the world. For instance, the gesture of swiping and the movement that displaces visual matter, both fully integrated to common handlings of digital material, are commonly associated with relatively new display equipment; yet, such association was not created ex nihilo. To look at earlier manifestations of the particular form of visual syntax concerned, as well as the ways in which it grew out of the gestures of swiping, is to point to key aspects of a shifting relationship between viewer, screen and image. A genealogy of the gesture of swiping might include leafing through pages (as we know from "vintage" electronic book designs where the interface mimics the pageturning effect), and throw into relief the efficiency and standardised nature of the gesture encouraged by the friction-free fluidity of the digital interface-an observation I will return to in a moment. In the specific context of the viewing of images however, it proves most relevant to focus on the visual effect first, and turn to one of cinema's classic forms of transition: the wipe.

13 It is because it emerges as a prominent mode of handling screened images that the swipe is most directly evocative of the technique of the cinematic wipe. In contrast with the direct cut through which, in the editing process, one film sequence gives way directly to another, the wipe transition relies, like the swipe, on a gradual displacement: an image from a new sequence chases one from a different shot so that, for a brief instant, parts of both images appear on the screen, sharing the same frame. In common with today's screen-swiping, which applies primarily to still images or 
webpages, the cinematic wipe bears the trace of film's base material: the single still frame..$^{29}$ Following George Albert Smith's first experimentation with this novel form of shot-transition (Mary Jane's Mishap or, Don't Fool with the Paraffin, completed in 1903, features an upward wipe), the wipe became common at the beginning of cinema's silent era. Interestingly, Smith's film concerns a very messy woman who gets "swept off" by an explosion at the end, thus knowingly or unwittingly creating an initial connection between the cinematic device and the original meaning of "to wipe," as in cleaning dirt away.

The wipe progressively fell into disuse as strong continuity, requiring unobtrusive transitions, became narrative cinema's dominant editing strategy. It made a comeback in the late 1960s, however, and features prominently in the cinematography of baroque filmmakers such as Brian De Palma. Indeed, the use of the wipe transition in De Palma's classic horror film Carrie (1976) perfectly illustrates the essential difference between cinema's wipe and the swipe of tactile screens (it also, interestingly, extends the association of the wipe to feminine uncleanliness). In the famous scene of the prom ball, where the teenage Carrie, covered in blood, uses her kinetic powers to trap and kill the classmates who bullied her, De Palma combines wipe transitions with split screens to underscore the way Carrie can make distant objects move, and in particular how she shuts the doors through the power of her mind. It is as if an invisible hand were simultaneously swiping the cinema screen and the doors featured in the image: a supra-human, disembodied, "swipe-to-lock" effect, not unlike the kind of touchless neuro-functions on which computer scientists are currently working. Except, of course, that the film is designed for a spectator who is also a helpless observer. Shots succeed each other, doors close through invisible force, the spectator knows something awful is coming but there is nothing he or she can do: the mix of knowingness and powerlessness is typical of horror cinema's mode of viewing; indeed, it is part of the game.

To compare the cinematic wipe with the touchscreen swipe, therefore, is to foreground the core change in the recent evolution of the regimes of the gaze. The film spectator, who sits in a cinema, has no means to influence the movement of the images, this surrendering to the movement and rhythm of the film being a condition of her pleasure and of her attentive gaze. In contrast, the viewer/user who watches moving images on his television with the remote in hand, or on his computer or iPad, ready to interface via the keyboard or tactile screen, may take control of the images' appearance, stopping or reverting their flow at any time, but also modifying the rhythm and format of their display at will. ${ }^{30}$ In a much more immediate, precise and systemic way than when leafing through the pages of a picture book or using a remote control, tactile screens couple vision and touch in a way that subjects the movement and presence of the visual content to the control of the hand or finger ${ }^{31}$-and soon, if we are to believe the latest experiments in this domain, to neuro-signals that may bring us back full circle to Carrie's telekinesis and the swipe-as-wipe ${ }^{32}$.

16 With its focus on the articulation of touch and gaze, presented as a filmed sequence on a large screen, Hirschhorn's installation places us in a typically reflexive position in regards to classical watching versus touch-and-see viewing: though it concerns the tactile handling of images, the piece offers itself as a traditional video display. Standing or sitting in front of the video screen, we cannot, no more than the traditional cinema spectator, intervene to modify that which plays out in front of our eyes (hence in 
Touching Reality, the swipe, filmed, effectively reverts into the wipe); we are invited to merely observe the familiar gestures that would normally allow us to interface with the image. The dispositif thus operates as a process of distantiation or estrangement, and in the shift back from "user" to spectator, the dismal gap that opens between the filmed gestures and the images manipulated by the hand comes to the fore.

\section{Regarding the pain of others}

In its simultaneous treatment of distressing material and operational gestures, Touching Reality hovers at the frontier between the obscene and the grotesque. The superimposition of the gestures with the content of the photographs generates an incongruous and disturbing combination of two registers that are intuitively, and for historical reasons, considered antonymic: full, unbearable horror on the one hand, and functionality and efficiency on the other. The more dreadful the content of the images, the more inappropriate the swiftness and competence of the hand and the effectiveness of the device may seem. The discrepancy is felt with particular acuity as the fluid manipulations evoke, in the nimbleness of the touch, the small tapping and the caressing of the surface by the tip of a finger, a form of nonchalant detachment. Here, gestures reveal their palimpsest-like dimension..$^{33} \mathrm{~A}$ set of connotations normally overlaid by the purely functional come to the fore anew. Underneath the apparent neutrality of the swipe, one may be reminded, for instance, of the light, gentle brush of a finger used when touching a precious object, or the hand or face of a person who is dear to us.

In the awkward fusion of horror and the tactile interface, such buried meanings resurface by default, pointing to the kind of processes of alienation that Flusser associated with the gestures derived from semi-automated devices: if such gestures express a way of being in the world, a Gestimmtheit, then efficiency comes to mind, coupled with indifference. Indeed, even if punctuated by gestures that suggest a degree of curiosity or voyeurism, as in the zoom and pinch, the swipe is designed primarily for the expert and swift manipulation of visual matter: it encourages a glancing or skimming through rather than an attentive viewing.

19 This obviously contributes to the uneasiness of the spectacle, the sense of a symbolic violence effected via the handling of images that are testimonies of terrible suffering: for, as we know from the now classic theorisation of its "economy," as attention is increasingly turned into a commodity, so does value become indexed to attention and time. In today's accelerated viewing and communicating protocols attention is scarce and therefore precious, and a contrario, that which is granted little or no attention is of little or no value. ${ }^{34}$

Gestures such as the swipe are conceived primarily for a superficial engagement with content and the notion of an "epidermal" use of tactile devices is to be understood in this sense of superficiality rather than in the sense of reversible physical contact. First and foremost, to swipe is to efficiently glide through a large quantity of data. The lightness of the gesture, the slight brush of the fingers that allows for a fluid, frictionfree journey from one frame to the next, promotes a mode of viewing that belongs to the regime of the overview. Affect, in particular where it might give way to emotions that derive from concern and interest, such as anger, or sadness, does not go well with the process of superficial and fluid overview. ${ }^{35}$ Strong emotion rhymes with friction, it 
makes us pause, it often renders us ineffective. And if a caress may express curiosity or affection through a light and elusive touch, the affectionate or desiring touch obviously does not involve the immediate and intentional disappearance of its object, but on the contrary, a sense of enhanced co-presence.

21 The absence of affect is thus more acutely felt as it relates to touch, that is, following the teachings of Maurice Merleau-Ponty-and, more recently, the writings of Giuliana Bruno-the one amongst our senses that is reciprocal: that which I touch touches me back. ${ }^{36}$ Here, obviously, what is being touched is the cold surface of a screen, not the bodies whose images the device displays, not even a material photographic representation, a picture that would bear the marks of handling. What potentially supplements the absence or lack manifested in the mediation of touch via the flat, smooth screen, is vision. To look, for Merleau-Ponty, is to touch with one's eyes, from a distance. ${ }^{37}$ To look thus creates a form of reciprocity: I can be "touched" by what I see. Yet, here, Hirschhorn appears to denounce the conditioning, via tactile interfaces, of visual perception by a kind of touch that works to destroy that sense of reversibility and thus, contributes to de-humanising tactile gestures.

Simultaneously confronted with the gesture and the object to which it applies, the spectator watching Hirschhorn's video searches in vain for a trace of empathy, a sign of how the sight of these awful images may affect the person who manipulates them via the touch screen. In its recording of the faceless controlling of visual matter through a tactile screen, Touching Reality reveals a "moving" that has lost its connection to emotion, and only applies to moving in the sense of chasing or moving away ${ }^{38}$ Hence the connection between the wipe and the swipe comes to the fore again: after all, as mentioned before, prior to designating an element of cinematographic grammar, to wipe was first synonymous with to efface, take away a stain or clean a surface. Similarly, to swipe, in its original meaning, is to brush dirt away. ${ }^{39}$ And the violence that haunts the contemporary uses of the term is not merely implicit: after all, to swipe also means to deliver a blow.

Taking heed of Flusser's approach, we should also account for embedded cultural codes that tend to become implied when associated with routine gestures. When considered in the context of a western culture that traditionally valorises the right over the left for instance, gestures applied to digital devices retain traditional semantic features: as in Hirschhorn's video, we tend to swipe from right to left, consigning the image we sent ad sinistram to oblivion..$^{40}$ Equally significant is the process of commodification we associate with the gestures filmed in Touching Reality, and which here applies to images of violence: the gestures, the swipe, but also the pinch and zoom, are part and parcel of the operating system of tactile devices now distributed by the main brands of digital technology manufacturers. It is through their resemblance with a "demo," and the undifferentiated regime of display to which the device's interfaces subject all imagesfrom advertisements to entertainment to documentary footage-that the recorded gestures, applied to images of dead bodies, are felt to perform a kind of symbolic violence.

24 The contrast between the destroyed bodies and the activity of the hand works to foreground the "epidermal" or purely functional quality of touch when subsumed by the activation of the interface. To further insist on the absence of reversibility, the artist establishes a familiar dichotomy between the operating hand and the bodies on display. In spite of the mutilations, of the tenuous clues that some of these images 
provide, these bodies clearly belong outside of the western world. They evoke the conflict zones of sub-Saharan Africa and the Middle East. Consciously or unconsciously, to western observers they may appear as the remains of "ungrievable lives," to paraphrase Judith Butler. ${ }^{41}$ In his critical evaluation of Hirschhorn's work, Dork Zabunyan draws on the ongoing debate about the ethics of looking, and turns to Jacques Rancière to denounce the Manichean confusion of hypervisibilty with freedom of information. ${ }^{42}$ The bodies whose photographs are shown in the video are clearly the bodies of "others," and, as Zabunyan points out, they are even more easily put on display that they are not protected by the principle of dignity that applies to the images of victims who died of terrorist acts in western countries. ${ }^{43}$

The hand, in contrast, is that of a Caucasian woman, a perfectly manicured hand. One can only wonder about the artist's intention here, in what looks like a rather blunt demonstration combined with a perplexing strategy of withdrawal. ${ }^{44}$ We cannot but take notice of the classic use of the female body part, ${ }^{45}$ the beautiful hand performing as a kind of moving ornament, in an activity that also bears the troubling echo of the gesture of cleaning once associated with the term swipe. This choice of a feminine hand as a prop has further implications, hardly counterpointed by a would-be ironical and critical intent. For it ensures there can be no confusion between the user's hand whose activity is under scrutiny and that of the artist, who might have filmed the video, but conveniently distances himself from the final dispositif. ${ }^{46}$

This mise en scène renders even more blatant and perplexing the implicit or explicit objectification of the "other" as classically denounced by Susan Sontag in her last essay, Regarding the Pain of Others (2003). Sontag condemns the long-lasting clichéd representations of the "other" as the one who is incapable of governing him or herself, incapable of taking care of him or herself-a discourse that implicitly and retrospectively justifies the colonial project. Her observations take on an eerie appositeness in the context of Touching Reality for here the gestures of the hand, pinching, and zooming in on the destroyed bodies as if seeking a diagnostic, are somewhat redolent, in their detached precision, of a medical examination.

\section{Filmed gestures and the persistence of the attentive gaze}

27 Yet there is a facet of Touching Reality that arguably grants Hirschhorn's work a different critical dimension: the reflexive mode of display that transforms individual reception into a collective experience. Whereas the viewing process that the video documents is typical of that of a separate, isolated user, the resulting installation, designed to be presented in the public space of a gallery or museum, is destined to a gaze that is both distanced, public, and shared. ${ }^{47}$

28

If the filmed gestures speak of alienation and the destroyed bodies of objectification and misuse, the watching together, publicly, thus reopens the possibility of a joint reaction that may simply express itself in the need to bestow the work, and, therefore, the images it displays, attentive time. Granted, to entertain such possibility without qualification would be to eschew the vexed question of the quality of the reception of time-based art in the museum and gallery space. If the "white cube" versus "black box" debate-the "free" and distracted roaming of the gallery visitor versus the fixed but 
sustained spectatorial engagement of the cinema goer-resonates with, and extends, the often-reiterated critical assessment of the regimes of viewing offered by mobile, portable screens, it holds undeniable topicality where the sensitive content of a piece like Touching Reality is concerned.

The question of the possibility, and indeed, value, of attentive viewing has been the subject of a heated discussion opposing art and film historians ever since moving images became a staple of art exhibitions. ${ }^{48}$ On the one hand, gallery viewing breaks the "illusion" of transparent, unmediated representation bred by the immersive darkness of the cinema, allowing the exhibition visitor to remain aware of the apparatus and context of display, and to circulate and choose which works to dedicate time to, and therefore, theoretically, be more actively involved in the experience. On the other, the reception of film and video in the gallery and museum has been compared to forms of zapping, swiping, and window shopping. In the gallery, one often cannot, literally, swipe or scroll through, but one can always stroll amongst images. The questions raised by critics of the "economy of attention" thus emerge with particular force as timebased works vie for the attention of a distracted visitor who is intent on getting a sample of all the art on display, and therefore unlikely to spend the time necessary to watch a whole video. Moreover, since in the white cube of the gallery, art works are not presented separately and in isolation, viewing is necessarily comparative. A piece like Hirschhorn's Touching Reality, which relies on the rapid succession of a collection of images, raises the obvious questions of de-contextualisation and the un-differentiated navigation of sensitive material, the images that follow one another refer to different situations of conflict and destruction that remain unidentified. ${ }^{49}$ As a single work, presented as part of a group of other exhibits, its reception is conditioned by its potential cohabitation with radically different kinds of images or works of art..$^{50}$

\section{Conclusion}

Exploring elements of historical continuity in our treatment of images, W.J.T. Mitchell has pointed out the persistence of certain archaisms that may, to an extent, counterpoint the banalization at work in their multiplication and circulation. No matter how much we know that an image is but an image, Mitchell observes, we are prone to invest it with a significance well beyond its status as picture, a material object "marked with colors and shapes" or a mere cluster of pixels. ${ }^{51}$ For all the effect of levelling which the repetition of the swipe subjects them to, the sharing of space and divided attention that the gallery space implies, and in spite of their decontextualisation and low cultural status as pictures, images such as the ones that Hirschhorn presents retain a power to insist, to claim our attention. If to view-a practice we associate with individual viewing devices-and to watch-as in the cinema -describe different qualities of spectatorial engagement, then it is in the mise en abyme of one mode of viewing-the iPad on which screen the pictures of the destroyed bodies appear-through the experience of watching it on a large video screen however, that the artist's installation work offers as a potentially reflexive and critical staging of our contemporary mode of spectatorship..$^{52}$

31 Though the work's entwined presentation, the individual gaze (of the iPad user) is potentially enfolded in the collective (the gallery audience), whilst in place of the epidermal folding of the swipe, the video offers itself as a form of reconnection or 
unfolding, where the violence of images is inseparable from the process that brings them to us and inexorably connects them to us. The filming of the gestures of the viewer-user, and their presentation to the gallery spectator, thus allows for the creation of the "proper distance" ${ }^{53}$ and the emergence of a conflict of affects that John Ellis describes as productive "emotional ambiguity": "This conflict is essentially one of emotional ambiguity, of knowing what you feel yet at the same time not knowing quite how to feel. This emotional ambiguity is underpinned by the constitutive ambiguity of the audiovisual, its status as there-ness yet textuality." ${ }^{54}$

Even if watching a video in a gallery space is, arguably, but a poor version of cinema's continuous, attentive and collective viewing, and of the sharing of emotions that it might entail,$^{55}$ in its estrangement of now routine gestures, Touching Reality nonetheless points to issues that tend to be effaced as newer modes of accessing images-mobile, interactive, and discrete-become ubiquitous: the neutralization of gestures and gaze, the impoverishment of a visual experience increasingly mediated through individual viewing devices, and the continuing import of watching together.

\section{BIBLIOGRAPHY}

Agamben, Giorgio. Qu'est-ce qu'un dispositif ? Paris: Payot \& Rivages, 2007.

André, Emmanuelle. "Seeing through the Fingertips." In Indefinite Visions: Cinema and the Attraction of Uncertainty, edited by Martine Beugnet, Allan Cameron and Arild Fetveit, 273-288. Edinburgh: Edinburgh UP, 2017.

Aumont, Jacques. Que reste-t-il du cinéma ? Paris: Vrin, 2013.

Beller, Jonathan. The Cinematic Mode of Production: Attention Economy and the Society of the Spectacle. Lebanon [NC]: University Press of New England, 2006.

Bellour, Raymond. La Querelle des dispositifs. Paris: P.O.L., 2010.

Beugnet, Martine. "Miniature Pleasures: On Watching Films on an iPhone." In Cinematicity in Media History, edited by Jeffrey Geiger and Karin Littau, 196-210. Edinburgh: Edinburgh UP, 2014.

-—-. L'attrait du flou. Crisnée: Yellow Now, 2017.

Blumlinger, Christa and Mathias Lavin. Geste filmé, gestes filmiques. Paris : Mimésis, 2017.

Boden, Margaret A. and Ernest A. Edmonds From Fingers to Digits. An Artificial Aesthetic.

Cambridge[Mass.]: MIT, 2019.

Bruno, Giuliana. Surface. Matters of Aesthetics, Materiality and Media. Chicago: The University of Chicago Press, 2014.

Bublitz, Christoph, Steffen Steinert, Steffen, Jox, Ralf and Orsolya Friedrich. "Doing Things with Thoughts: Brain-Computer Interfaces and Disembodied Agency." Philosophy Technology, (March 2018). https://link.springer.com/article/10.1007/s13347-018-0308-4 <accessed on November 11, 2020>

Butler, Judith. Frames of War: When is Life Grievable? London: Verso, 2009. 
Casetti, Francesco and Sara Sampietro. "With Eyes and Hands: The Relocation of Cinema Into the iPhone." In Moving data - The iphone and the Future of Media, edited by Pelle Snickars et Patrick Vonderau, 19-33. New York: Columbia UP, 2012.

Citton, Yves. Pour une écologie de l'attention. Paris: Le Seuil, 2014.

Coleman, Rebecca and Liz Oakley-Brown. "Visualizing Surfaces, Surfacing Vision: Introduction." Theory, Culture \& Society 34, no. 7-8, (2017): 5-27.

Crary, Jonathan. Suspensions of Perception. Attention, Spectacle \& Modern Culture. Cambridge [Mass.]: MIT Press, 2001.

--_. 24/7: Late Capitalism and the Ends of Sleep. New York: Verso, 2013.

Davenport, Thomas H. and John C. Beck. Attention Economy: Understanding the New Currency of Business. Boston: Harvard Business Press, 2002.

Davis, Whitney. A General Theory of Visual Culture. Princeton: Princeton UP, 2011.

de Kuyper, Eric and Emile Pope. "L'Autre Histoire du cinema ou la perte du spectacle : Qui gagne, qui perd ? » In In the very beginning, at the very end, edited by Francesco Casetti, Jane Gaines and Valentina Re, 143-51. Udine: Udine Forum, 2009.

Dubois, Philippe, Lúcia Ramos Monteiro and Alessandro Bordin, eds. Oui, c'est du cinéma: formes et espaces de l'image en mouvement. Udine: Pasian di Prato, 2009.

Ellis, John. "What Are We Expected to Feel? Witness, Textuality and the Audiovisual." Screen 50, no. 1, (2009): 67-76.

Fedorova, Ksenia. Tactics of Interfacing. Encoding Affect in Art and Technology. Cambridge [Mass.]: MIT, 2020.

Flusser, Vilém. Für eine Philosophie des Fotografie. Göttingen: European Photography, 1983. Towards A Philosophy of Photography. Translated by Anthony Mathews. London: Reaktion Books, 2000.

---. Les Gestes. Bandol-Paris: Al Dante \& Aka, 2014. Gestures. Translated by Nancy Ann Roth. Minneapolis: University of Minnesota Press, 2014.

Fowler, Catherine. "Room for Experiment: Gallery Films and Vertical Time from Maya Deren to Eija Liisa Ahtila," Screen 45, no. 5, (2004): 324-34.

Gaudreault, André and Philippe Marion. La Fin du cinéma ? Un média en crise à l'ère du numérique. Paris: Armand Colin, 2013.

Grusin, Richard. "Radical Mediation.” Critical Inquiry 42, no. 1, (Autumn 2015): 124-48.

Hanich, Julian. "Watching a Film with Others: Towards a Theory of Collective Spectatorship." Screen 55, no. 3, (Autumn 2014): 338-59.

Hirschhorn, Thomas. Critical Laboratory. The Writings of Thomas Hirschhorn. Cambridge [Mass.]: MIT Press, 2013.

-_-."Pourquoi est-il important aujourd'hui de montrer et de regarder des images de corps humains détruits ?" In Que peut une image ?, edited by Dork Zabunyan, Carnets du BAL \#4, 106-116. Paris: Le BAL / Éditions Textuel / Centre National des Arts Plastiques, 2013.

Susanne Jaschko, "Space-time correlations focused in film objects and interactive video," Future Cinema, The Cinematic Imaginary after Film, Jeffrey Shaw et Peter Weibel (Eds.), ZKM-Zentrum für Kunst und Medientechnologie Karlsruhe/The MIT Press, Cambridge, MA, 2002, pp. 430-435, http://www.arpla.fr/canal20/adnm/?cat=110\&paged=3, <accessed on November 11, 2020>. 
Kuntzel, Thierry. “Le défilement.” La Revue d'Esthétique 2-3-4, (1973): 97-110.

Marks, Laura U. "Information, Secrets and Enigmas: an Enfolding-unfolding Aesthetics for Cinema." Screen 50, no. 1, (March 2009): 86-98.

Massumi, Brian. Parables for the Virtual: Movement, Affect, Sensation. Durham [NC]: Duke UP, 2002.

Merleau-Ponty, Maurice. Le Visible et l'Invisible. Paris: Gallimard, 1964.

Mitchell, W.J.T. What do Pictures Want? The Lives and Loves of Images. Chicago: The University of Chicago Press, 2004.

---. Cloning Terror. The War of Images, 9/11 to the Present. Chicago: The University of Chicago Press, 2011.

Monk, Philip. "Paint it Black: Curating the Temporal Image." In Projecting Questions? Mike Hoolboom's Invisible Man Between the Art Gallery and the Movie Theatre. Toronto: The Art Gallery of York University, 2004.

Osborne, Peter. "Distracted Reception: Time, Art, and Technology." In Time Zones, edited by Jessica Morgan and Gregor Muir, 66-75. London: Tate Publishing, 2004.

Rancière, Jacques. Le Spectateur émancipé. Paris: La Fabrique, 2008.

Serres, Michel. Le Parasite. Paris: Grasset, 1980.

Shapiro, Roberta and Nathalie Heinich. "When is Artification?" Contemporary Aesthetics 4, (2012). http://hdl.handle.net/2027/spo.7523862.spec.409, <accessed on November 11, 2020>.

Silverstone, Roger. Media and Morality: on the Rise of the Mediapolis. Cambridge: Polity Press, 2007.

Steinert, Steffen, Christoph Bublitz, Ralf Jox, Ralf and Orsolya Friedriech. "Doing Things with Thoughts: Brain-Computer Interfaces and Disembodied Agency," Philosophy \& Technology 32, 457-482 (2019), https://link.springer.com/article/10.1007/s13347-018-0308-4, <accessed on November 11, 2020>.

Steyerl, Hito. "In Defense of the Poor Image." e-flux journal 10, (November 2009). http://www.eflux.com/journal/10/61362/in-defense-of-the-poor-image, <accessed on November 11, 2020>.

- - . "How to Kill People: A Problem of Design." In Duty Free Art. Art in the Age of Planetary Civil War. London: Verso, 2017.

Woolf, Virginia. Three Guineas. London: Hogarth Press, 1938.

Zabunyan, Dork. "Devant l'effroyable - Art des images et principe de dignité," Art press 2 41, (maijuillet 2016): 75-83.

\section{NOTES}

1. Vilém Flusser, Les Gestes (Bandol-Paris: Al Dante \& Aka, 2014), 115. Publications of Flusser's work in different languages tend not to include the same texts even when they bear the same title (Flusser himself wrote in several languages). In what follows, I will therefore refer alternatively to publications in French and in English. Translations from the French are mine.

2. The term is here taken in its current meaning, as a historical phenomenon that lies at "the intersection of vision (and visibility) and culture (and visible culturality)." Davis, A General Theory of Visual Culture (Princeton: Princeton University Press, 2011), 8.

3. More than ever, our ability to decipher images needs to be supplemented by a critical understanding of the conditions of reception, as popularized for instance by John Berger's work. 
4. As pointed out by Richard Grusin. See Richard Grusin, "Radical Mediation," Critical Inquiry 42, no. 1, (Autumn 2015): 124-48.

5. Flusser's phenomenology of gesture focuses, amongst other phenomena, on the production of technical images, specifically photography. Flusser devoted a chapter of Les Gestes to photography, as well as a separate volume: Für eine Philosophie des Fotografie? (Göttingen: European Photography, 1983). Towards A Philosophy of Photography?, trans. Anthony Mathews (London: Reaktion Books, 2000).

6. On the history and aesthetics of the relation between hand and eye, see the work of Emmanuelle André, including "Seeing through the Fingertips," in Indefinite Visions: Cinema and the Attraction of Uncertainty, ed. Martine Beugnet, Allan Cameron and Arild Fetveit (Edinburgh: Edinburgh UP, 2017), 273-88.

7. Flusser writes well before digital encoding became the predominant form of communication and imaging. The distinction he makes between one's ability to simply operate the machine (which turns us into a good "operator") and that of the appropriation and diversion of technology towards unintended usages and unexpected effects remains completely topical however. See Towards a Philosophy of Photography. See also Martine Beugnet, L'attrait du flou (Crisnée: Yellow Now, 2017), 115-18.

8. By "surfacing" Rebecca Coleman and Liz Oakley-Brown describe how surfaces themselves become sites of visualisation: "Visualizing Surfaces, Surfacing Vision: Introduction," Theory, Culture \& Society 34, no. 7-8, (2017): 5-27.

9. Jonathan Beller, The Cinematic Mode of Production: Attention Economy and the Society of the Spectacle (Lebanon [NC]: University Press of New England, 2006); Yves Citton, Pour une écologie de l'attention (Paris: Le Seuil, 2014); Jonathan Crary, Suspensions of Perception -Attention, Spectacle \& Modern Culture (Cambridge [Mass.]: MIT Press, 2001) and 24/7: Late Capitalism and the Ends of Sleep (New York: Verso, 2013).

10. Doing so, I am aware that I am at odds with one of the dominant trends in media and software studies. Inspired by Gilbert Simondon's approach, it advocates an integrated techno-aesthetic approach based on a naturalized conception of the human-technology relationship. See, amongst other recent publications, Ksenia Fedorova, Tactics of Interfacing. Encoding Affect in Art and Technology (Cambridge [Mass.]: MIT, 2020) and Margaret A. Boden and Ernest A. Edmonds From Fingers to Digits. An Artificial Aesthetic (Cambridge[Mass.]: MIT, 2019).

11. For a recent contribution to the field, see Christa Blumlinger and Mathias Lavin, Geste filmé, gestes filmiques (Paris : Mimésis, 2017).

12. Hito Steyerl, "In Defense of the Poor Image," e-flux journal 10, (November 2009) http://www.eflux.com/journal/10/61362/in-defense-of-the-poor-image, <accessed November 11, 2020>. See also Hito Steyerl, "How to Kill People: A Problem of Design," in Duty Free Art. Art in the Age of Planetary Civil War (London: Verso, 2017).

13. Published in English in Thomas Hirschhorn, Critical Laboratory. The Writings of Thomas Hirschhorn (Cambridge [Mass.]: MIT Press, 2013), and in French as "Pourquoi est-il important aujourd'hui de montrer et de regarder des images de corps humains détruits?", in Que peut une image ?, ed. Dork Zabunyan, Carnets du BAL \#4, (Paris: Le BAL / Éditions Textuel / Centre National des Arts Plastiques, 2013): 106-16. See also: http://www.dailymotion.com/video/xshflo_thomashirschhorn-insoutenables-destructions-du-corps_creation, <accessed on November 11, 2020>.

14. W.J.T. Mitchell, Cloning Terror. The War of Images, 9/11 to the Present (Chicago: The University of Chicago Press, 2011).

15. Laura U. Marks, "Information, Secrets and Enigmas: an Enfolding-unfolding Aesthetics for Cinema," Screen 50, no. 1, (March 2009): 86-98.

16. "The universe of images contains all possible images in a virtual state, and certain images arise from it, becoming actual." It is worth keeping in mind that for Laura Marks, forms of 
enfolding include cinematic style, as well as the algorithmic language. Marks, "Information, Secrets and Enigmas," 87.

17. "Images are in a position to 'unfold' information, and thus to connect it back to the world." Marks, "Information, Secrets and Enigmas," 87.

18. Steyerl, "In Defense of the Poor Image."

19. In "Visualising Surfaces, Surfacing Vision," Coleman and Oakley point out that surfaces are means by which particular ideas are visualized, but that, in turn, vision is constituted by the particular kind of surface where it becomes located, and by the kind of interactions such positing implies.

20. As Michel Serres explains, "systems work because they don't work." Where interfacing ceases to be perceived as such, when we stop to register its parasitical presence, then it fails to properly "mediate" Le Parasite (Paris: Grasset, 1980), p.107. Similarly, Alexander Galloway, notes that, when an interface becomes "as naturalized as air or as common as dust," it is merely superimposed to the existing mediatic layers. We then fail to engage with its potential meaningmaking function which he coins the "intraface," that is, the relationship "within the object between the aesthetic form of the piece and the larger historical material context in which it is situated." "The Unworkable Interface," in The Visual Culture Reader, ed. Nicholas Mirzoeff (London: Routledge, 2013), 619-636.

21. Dispositif is understood in its classical meaning, as the way the apparatus that presides over the display of the images is put together so as to facilitate and mediate the viewer's access to and eventual identification with the visual content. On the recent evolution of media dispositifs, see Giorgio Agamben, Qu'est-ce qu'un dispositif? (2006; Paris: Payot \& Rivages, 2007).

22. I am stretching somewhat the meaning of the term as proposed by sociologists Roberta Shapiro and Nathalie Heinich. In their work, the term artification designates the process whereby cultural productions that do not originate in recognized artistic practices come to be considered as art works or art forms. Roberta Shapiro and Nathalie Heinich, "When is Artification?", Contemporary Aesthetics 4, (2012). http://hdl.handle.net/2027/spo.7523862.spec.409 2 <accessed on November 11, 2020>.

23. Flusser, Les Gestes, 327.

24. Whilst suggesting that "attunement" might be an adequate translation for Gestimmheit, translator Nancy Ann Roth settles on "affect" - an unsatisfying solution as it draws the meaning of the German term towards the experiential to the detriment of its cultural dimension (both of which my "being in the world" attempts to capture) and fails to account for the uses of the term "affect" in art and media studies. See translator's notes in Vilém Flusser, Gestures

(Minneapolis: University of Minnesota Press, 2014), 177-78.

25. Flusser, Gestes, 319-29. See also the introduction to Gestures, 1-9.

26. Flusser, Gestures, 10-12; Les Gestes, 307-308. In the shift from "why" to "how", he argues, the machine is increasingly perceived "as a system that can serve as a model for the world,"Gestures, 14.

27. Talking about the ways in which the iPhone may be used to watch moving images, Francesco Casetti and Sara Sampietro designate "epidermal" a mode of utilization where the technical, operational dimension dominates the user's activities. The content is more or less important, what matters is the mastery of the device's various functionalities. Francesco Casetti and Sara Sampietro, "With Eyes and Hands: The Relocation of Cinema Into the iPhone," in Moving data-The iphone and the Future of Media, ed. Pelle Snickars and Patrick Vonderau (New York: Columbia University Press, 2012), 19-33. See also Martine Beugnet, "Miniature Pleasures: On Watching Films on an iPhone," in Cinematicity in Media History, ed. Jeffrey Geiger and Karin Littau (Edinburgh: Edinburgh University Press, 2014), 196-210.

28. Flusser, Les Gestes, 104. 
29. The swipe gesture, like the wipe, draws attention not on depth and perspectival space, but on the instability of the field of vision, and the relativity of such principles in the spatio-temporal constructs of moving image media. For a discussion of the impact of digital aesthetics on montage and perspective see Emmanuelle André, "Seeing Through the Fingertips," in Indefinite Visions: Cinema and the Attrations of Uncertainty, ed. Martine Beugnet, Allan Cameron and Arild Fetveit (Edinburgh: Edinburgh U.P, 2015), 273-288, and Susanne Jaschko, "Space-time correlations focused in film objects and interactive video," Future Cinema, The Cinematic Imaginary after Film, Jeffrey Shaw et Peter Weibel (Eds.), ZKM-Zentrum für Kunst und Medientechnologie Karlsruhe/The MIT Press, Cambridge, MA, 2002, pp. 430-435, http://www.arpla.fr/canal20/ adnm/?cat $=110$ \&paged $=3<$ accessed on November $11,2020>$.

30. See later footnote on the etymology of to move / emovere. The swiping or scrolling belongs to a radically different regime of the moving image than the one Thierry Kuntzel once associated with the movement of an animation film passing through a projector. Kuntzel talked of the film's power of émouvoir ("moving" both in the sense of movement and affect), derived from the mysterious and inexorable movement of the images that come into view then escape, activating the desire of the spectator to see who is helpless in altering its flow. Thierry Kuntzel, "Le défilement," La Revue d'Esthétique 2-3-4, (1973): 97-110.

31. This kind of interface may be alien to cinema's dispositif, but it nonetheless features prominently in science fiction films, as in the classic scene from Minority Report (2002) where Tom Cruise deftly rearranges virtual contents, manœuvering transparencies around, and occasionally and decisively sweeping away an irrelevant frames.

32. See for instance: Steffen Steinert, Christoph Bublitz, Ralf Jox, and Orsolya Friedrich's article on BCIs (Brain-Computer Interfaces): "Doing Things with Thoughts: Brain-Computer Interfaces and Disembodied Agency," Philosophy \& Technology (March 2018), https://www.researchgate.net/ publication/323686843_Doing_Things_with_Thoughts_Brain-

Computer_Interfaces_and_Disembodied_Agency, <accessed on November 11, 2020>.

33. Following the iconological method, one could compare and contrast the delicate gestures of hands found in renaissance and modern paintings with the stylized representations of touch screen gestures in designers' reference guides. Art memes have already made such connections.

34. Thomas H. Davenport and John C. Beck, Attention Economy: Understanding the New Currency of Business (Boston: Harvard Business Press, 2002).

35. I am following Brian Massumi's definition of affect as an unqualified intensity, to be differentiated from emotion. Contrary to emotion, which fits through "action-reaction circuits" into "meaning and function," affect does not yet belong to "semantically or semiotically formed progressions." Brian Massumi, Parables for the Virtual: Movement, Affect, Sensation (Durham [NC]: Duke University Press, 2002), 28.

36. Giuliana Bruno, Surface. Matters of Aesthetics, Materiality and Media (Chicago: The University of Chicago Press, 2014).

37. Maurice Merleau-Ponty, Le Visible et l'Invisible (Paris: Gallimard, 1964), 174-75.

38. Not unlike the meaning of wipe and swipe, the latin verb emovere means to move something out of somewhere, to dislodge, to chase away or disperse (hence, the later meanings associated with movement but also with emotion as mental agitation, with "being beside oneself"). Given that the isolated "e" now tends to stand for electronic, one can anticipate how "e-motion," in newspeak, may serve to describe the interface-designed manipulation of images.

39. An observation that puts into proper light applications such as Tinder, where the swipe is used to "like" (right) or "dislike" (left), that is, to archive or erase the profile of potential dating partners.

40. Lest one swipes backwards, as if retrieving an item from a virtual bin. The touchscreen scroll, on the other hand, is closely connected to the pre-digital meaning of the term, and implies 
continuity; going up-and-down is not felt, as in the wipe or swipe, as a rupture (going from one kind of object, page or material to another).

41. Judith Butler, Frames of War: When is Life Grievable? (London: Verso, 2009).

42. Jacques Rancière, le Spectateur émancipé (Paris, La Fabrique, 2008), 33; quoted in Dork Zabunyan, "Devant l'effroyable - Art des images et principe de dignité," Art press 241 , (mai-juillet 2016), 78.

43. Zabunyan, "Devant l'effroyable," 75-83. A work of art like Touching Reality also raises the question of the relationship of documentary images and art. In an op-ed article historian Philippe Artières summarized the issues at stake in relation to George Didi-Huberman's exhibition Soulèvements (Jeu de Paume, January 2017). Pointing to the show's undifferentiated absorption of historically and politically grounded material, Artières denounced the levelling effect of its assemblage of decontextualized images. "L'histoire sociale n'est pas de l'art !," Libération (8 janvier 2017).

44. A choice one may relate to Hirschhorn's characteristic denunciation of commercial imagery. Through the years, Hirschhorn has produced series of collages, including Collage-Truth (2012), Easycollage (2014), or Ur-Collage (2008) in which he explores topics similar to that of Touching Reality, assembling elements extracted from advertisements with fragments of documentary photographs, to establish parallels between the former's idealized and the latter's destroyed bodies.

45. A possible countershot to Hirshhorn's images might be found in the classic scene in Agnès Varda's Les glaneurs et la glaneuse (2000), where the film director holds a video camera in one hand so as to film her other hand: the hand of an ageing woman who assumes responsibility for, and creative ownership of, her work.

46. In its use of a feminine hand, Hirshhorn's postulate is a far cry from Virginia Woolf's argument about war, images and genre in her essay Three Guineas, where she famously argued that there is a profound difference in the way men and women look at images of war. For women, such images are doubly inacceptable, she says, for women reject war in all its forms, even when it is presented as a just or necessary conflict. Virginia Woolf Three Guineas (London: Hogarth Press, 1938).

47. I have seen the work on two occasions, at the Palais de Tokyo, in Paris, in 2012 (as part of the Intense Proximity exhibition), and at the FRAC Poitou-Charente, in Angoulême, in 2015. On both occasions, I watched the video in the company of a handful of other visitors.

48. See, amongst others, Jacques Aumont, Que reste-t-il du cinéma ? (Paris: Vrin, 2013); the introduction to Raymond Bellour, La Querelle des dispositifs, Paris: P.O.L., 2010; Eric de Kuyper and Emile Pope, "L'Autre Histoire du cinema ou la perte du spectacle : Qui gagne, qui perd ?," in In the very beginning, at the very end, ed. Francesco Casetti, Jane Gaines, and Valentina Re (Udine: Udine Forum, 2009), 143-51; Catherine Fowler, "Room for Experiment: Gallery Films and Vertical Time from Maya Deren to Eija Liisa Ahtila," Screen 45, no. 5, (2004): 324-34; André Gaudreault and Philippe Marion, La Fin du cinéma ? Un média en crise à l'ère du numérique (Paris: Armand Colin, 2013); Philip Monk, "Paint it Black: Curating the Temporal Image", Projecting Questions? Mike Hoolboom's Invisible Man Between the Art Gallery and the Movie Theatre (Toronto: The Art Gallery of York University, 2004); Peter Osborne, "Distracted Reception: Time, Art, and Technology," in Time Zones ed. Jessica Morgan and Gregor Muir (London: Tate Publishing, 2004), 66-75; Philippe Dubois, Lúcia Ramos Monteiro and Alessandro Bordin, eds., Oui, c'est du cinéma: formes et espaces de l'image en mouvement (Udine: Pasian di Prato, 2009).

49. Sontag criticizes Sebastião Salgado's "Family of Man-style rhetoric" and what she sees as its reductive approach to the depiction of misery where "the powerless are not named in the captions." Susan Sontag, Regarding the Pain of Others (New York: Picador, 2003), 78. Similar issues may be raised in relation to a number of recent art projects inspired by the contemporary return to a Warburgian aesthetic, as exemplified by Georges Didi-Huberman and Arno Gisinger's 
exhibition, Nouvelles histoires de fantômes. In its version for the Palais de Tokyo, (Paris, February 14 - September 7, 2014) extracts from fiction and documentary films depicting suffering were projected on the gallery floor side by side. Though the names of the films were given, the context for the depicted events were not explained. The search for the iconic resonances and universality of suffering thus arguably results in the kind of "globalizing" effect that Sontag denounced as "too epic to be much changed by any local political intervention." Sontag, Regarding the Pain of Others, 79.

50. This problematic of the shared exhibition space is echoed in Sontag's discussion of the documentary photograph printed in magazines; she recalls the first appearance of Robert Capa's famous photograph of the shot freedom fighter in the pages of Life, next to an advertisement for hair cream. Sontag, Regarding the Pain of Others, 120.

51. W.J.T. Mitchell, What do Pictures Want? The Lives and Loves of Images (Chicago: The University of Chicago Press, 2004), 31-34.

52. In the conclusion to Regarding the Pain of Others, Sontag suggests that cinema remains the medium most appropriate to a constructive confrontation with the suffering of others-not the cinema designed for the spectacular treatment of violence, but cinema as a representation constructed so as to account for the historical context of the events depicted, to be viewed without the encroachment of peripheral, extraneous material such as advertisement. "A narrative seems likely to be more effective than an image. Partly it is a question of the length of time one is obliged to look, to feel." Sontag, Regarding the Pain of Others, 122. Though the issue of (the kind of) narrative would need to be carefully unpacked, and that of the incorporeity of the gaze addressed, Sontag's observation remains topical in the way it points to spectatorial conditions and the experience of duration as dimensions of the cinema that contribute to creating a space where the necessary attentive contemplation allows for a reflexive, critical encounter.

53. By "proper distance," Silverstone means the distance, often not denied by media representations, between recognizing the other as "just like us" and acknowledging and valuing the difference of the other. Roger Silverstone, Media and Morality: on the Rise of the Mediapolis (Cambridge: Polity Press, 2007), 172, quoted in John Ellis, "What Are We Expected to Feel? Witness, Textuality and the Audiovisual", Screen 50, no. 1, (2009), 75.

54. Ellis, "What Are We Expected to Feel?," 75.

55. See Julian Hanich, "Watching a Film With Others: Towards a Theory of Collective Spectatorship," Screen 55, no. 3, (Autumn 2014): 338-59.

\section{ABSTRACTS}

Not only are we now surrounded by a plethora of images that derive from automatic mechanical protocols, "technical images" as Wilém Flusser would call them, but vision itself is controlled by technological processes-manually activated interfaces that condition the appearance of images in terms of size, quality and resolution, as well as duration. Our experience as viewers increasingly become that of "users": we touch the screen to activate a menu and select a resolution, to choose and enlarge an image, zoom into it or reduce its size, to start or pause a video, to scroll through or superimpose images, to slow down or speed up their course, to make them disappear. Not that the involvement of the hand turns the interface into the equivalent of a tool, which is a prolongation of the body. Unlike the tool, touch screens belong to the realm of 
the programmed machine. To evaluate the effect of technology over the culturality of gestures as well as vision was one of Flusser's key projects, one whose import comes to the fore with particular force in the digital era, when visuality appears to increasingly escape the realm of purely visual phenomenon. In what follows, I refer to Flusser's far-sighted work, as well as concepts of the fold as derived from Leibnitz and Gilles Deleuze by Laura U. Marks, in order to look at the ways in which interfaces and gestures, that are associated with tactile display devices, determine the form and effect of image reception in the context of our contemporary "economy of attention." To this end, I rely also on the description and critical assessment of a work of art by artist Thomas Hirschhorn, Touching Reality (2012), whose combination of classical video display with an interface, showing deliberately controversial images, brings the question of reception into sharp focus.

\section{INDEX}

Keywords: Thomas Hirschhorn, swipe, interface, hapticity, immersion

\section{AUTHOR}

\section{MARTINE BEUGNET}

Martine Beugnet is Professor of visual studies at the Université de Paris. She has written articles and essays on a wide range of film and media topics and has published five books, among which Claire Denis (Manchester University Press, 2004), Proust at the Movies (Ashgate, 2005), with Marion Schmidt, Cinema and Sensation: French Film and the Art of Transgression (Edinburgh UP, 2007, reissued 2012), and L'attrait du flou (Yellow Now, 2018). She has recently edited with Allan Cameron and Arild Fetveit, Indefinite Visions Cinema and the Attractions of Uncertainty, (Edinburgh UP, 2017). Le Cinéma et ses doubles: l'image de film à l'ère du foundfootage numérique et des écrans de poche is forthcoming (2021). She co-edits with Chris Ravetto the book series Studies in Film for Edinburgh UP.

Université de Paris, LARCA, CNRS, F-75013 Paris, France

martine.beugnet@u-paris.fr 